\title{
ASO Visual Abstract: Cancer-Related Fatigue after Esophageal Cancer Surgery-Impact of Postoperative Complications
}

\author{
Zhao Cheng, MD ${ }^{1}$, Asif Johar, MSc ${ }^{1}$, Magnus Nilsson, $\mathrm{MD}, \mathrm{PhD}^{2,3}$, and Pernilla Lagergren, $\mathrm{RN}$, $\mathrm{PhD}^{1,4}$ \\ ${ }^{1}$ Surgical Care Science, Department of Molecular Medicine and Surgery, Karolinska Institutet, Karolinska University \\ Hospital, Stockholm, Sweden; ${ }^{2}$ Division of Surgery, Department of Clinical Science, Intervention and Technology \\ (CLINTEC), Stockholm, Sweden; ${ }^{3}$ Department of Upper Abdominal Diseases, Karolinska University Hospital, Stockholm, \\ Sweden; ${ }^{4}$ Department of Surgery and Cancer, Imperial College, London, United Kingdom
}

Cancer-related fatigue increased and was not relieved for up to 2 years after esophageal cancer surgery. Medical complications and pulmonary complications, rather than surgical complications, were associated with increased cancer-related fatigue after esophagectomy (https://doi.org/ 10.1245/s10434-021-11049-z).

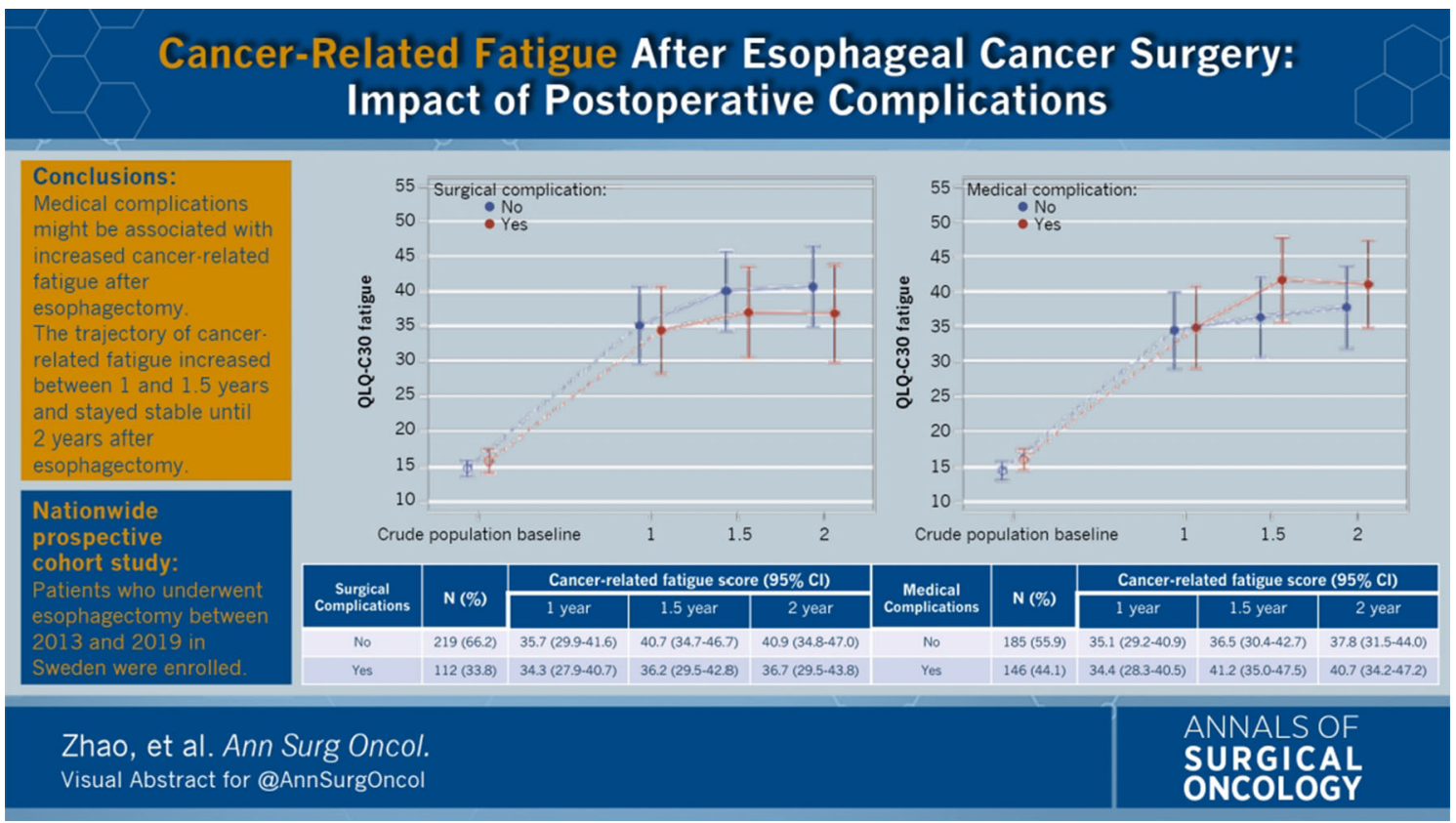

(C) Society of Surgical Oncology 2021

DISCLOSURE There are no conflict of interest.

Published Online: 10 January 2022

Publisher's Note Springer Nature remains neutral with regard to jurisdictional claims in published maps and institutional affiliations.

P. Lagergren, RN, PhD

e-mail: pernilla.lagergren@ki.se 